\title{
Introduction to the Minitrack on Global, International, and Cross-Cultural Issues in IS
}

\author{
Pnina Fichman \\ Indiana University Bloomington \\ fichman@indiana.edu \\ Edward W.N. Bernroider \\ Vienna University of Economics and Business \\ edward.bernroider@wu.ac.at
}

\begin{abstract}
Globalization has historically been tied to technological innovation, and the present era of a networked information society is no different. Information and communication technologies (ICTs) have provided the infrastructure for multinational businesses, created new cultural connections irrespective of geographic boundaries and distances, and allowed an increasingly mobile global population to be connected to their friends, families, and cultures no matter where they are. The issues surrounding global, international, and cross-cultural issues in Information Systems (IS) attracted much scholarly attention and have been explored under myriad contexts.
\end{abstract}

The Internet has transformed the way we work, learn, and play, the papers in this minitrack focus on the sociotechnical dynamics and the ways in which the
Internet affects people, groups, organizations, and societies, and in particular on the impact of global, international, and cross-cultural issues on ICT development, implementation and use across the globe.

Three papers are included in this year minitrack. The first, On the Importance of Considering Countryspecific Aspects on the Online-Market: An Example of Music Recommendation Considering CountrySpecific Mainstream, by Christine Bauer and Markus Schedl. The second, The Impact of National Culture on Mobile Commerce Adoption and Usage Intensity, by Timo Mandler and Colleagues. And the third, $A n$ Open Model for Researching the Role of Culture in Online Self-Disclosure, Christine Bauer, Katharina Sophie Schmid, and Christine Strauss. 